\title{
Penerapan Data Mining Menggunakan Task Market Basket Analysis Pada Transaksi Penjualan Barang di AB Mart dengan Algoritma Apriori
}

\author{
Andreas Lewis ${ }^{1, *}$, Muhammad Zarlis ${ }^{2}$, Zakarias Situmorang ${ }^{3}$ \\ ${ }^{1}$ Fakultas Teknik dan Ilmu Komputer, Prodi Magister Ilmu Komputer, Universitas Potensi Utama, Medan, Indonesia \\ ${ }^{2}$ Universitas Sumatera Utara, Medan, Indonesia \\ ${ }^{3}$ Universitas Katolik Santo Thomas Medan, Medan, Indonesia \\ Email: 1," lewis.munthe@gmail.com, ${ }^{2}$ m.zarlis@yahoo.com, ${ }^{3}$ zakaria65@yahoo.com \\ Email Penulis Korespondensi: lewis.munthe@gmail.com
}

\begin{abstract}
Abstrak-Data Mining adalah proses mengekstrasi informasi atau sesuatu yang yang menarik dari data yang ada didalam database sehingga menghasilkan informasi yang berharga dengan menggunakan teknik-teknik seperti clustering, estimasi, deskripsi, dan lain-lain. Berdasarkan observasi di AB Mart ada sebanyak 44 item produk yang datanya tidak terungkap. Permasalahan ini akan dipecahkan menggunakan analisis data mining. Tujuan penelitian iniMelakukan penerapan market basket analysis pada transaksi penjualan barang di AB Mart dengan algoritma apriori. Penelitian ini menggunakan susunan kerangka kerja yang jelas tahapannya yaitu Identifikasi masalah, Studi Literatur, Pengumpulan Data, Perhitungan \& Analisis Kaidah Asosiasi dengan algoritma apriori, pembentukan kaidah asosiasi dan pembuatan laporan. Hasil transaksi penjualan AB Mart pada bulan Agustus menghasilkan atau men-generate hubungan antar item produk belanja dimana $\%$ pembelian Pepsodent 115\%, Frisian Flag 96\%, Gula Pasir 96\%, Indomilk 93\%, dam Beras jempol 91\%. Kesimpulan dari penelitian ini menggunakan software Weka dengan algoritma apriori dimana menghasilkan hubungan asosiasi antara barang pepsodent dengan jumlah transaksi yang dibeli.
\end{abstract}

Kata Kunci:Data Mining; Market Basket Analysis; Algoritma Apriori

Abstract-Data Mining is the process of extracting information or something interesting from the data in the database so as to produce valuable information using techniques such as clustering, estimation, description, and others. Based on observations at $\mathrm{AB}$ Mart, there were 44 product items whose data was not revealed. This problem will be solved using data mining analysis. The purpose of this research is to apply market basket analysis to the sale of goods at AB Mart with the a priori algorithm. This research uses a clear structure of the framework, namely problem identification, literature study, data collection, calculation \& analysis of association rules with a priori algorithm, forming association rules and making reports . The results of the sales transaction of $\mathrm{AB}$ Mart in August resulted in or generated relationships between shopping product items where the\% purchase of Pepsodent was 115\%, Frisian Flag 96\%, Sugar 96\%, Indomilk 93\%, and Nasi Jempol 91\%. The conclusion of this research is using Weka software with a priori algorithm which produces an association relationship between pepsodent goods and the number of transactions purchased.

Keywords: Data Mining; Market Basket Analysis; Apriori Algorithm

\section{PENDAhUluan}

AB Mart beralamat di Jl. Batang Hari, Kuamang Kuning 1 SPA merupakan salah satu minimarket yang bergerak dalam bidang penjualan yang cukup lengkap, seperti kebutuhan pokok sehari-hari, makanan, minuman, peralatan rumah tangga, dan lainnya yang ditempatkan pada rak-rak atau etalase. Adapun permasalahan yang terjadi yang peneliti dapat dari Ibu Enggar Yuliawati sebagai pemilik toko saat melakukan wawancara, diantaranya penempatan barang yang belum sesuai dengan perilaku kebiasaan konsumen dalam membeli barang secara bersamaan dalam satu waktu. Sehingga membuat konsumen menanyakan dimana posisi barang yang mereka butuhkan serta akan mengalami keterlambatan dalam proses pembelian[1].

Berdasarkan data yang didapat dari pemilik AB Mart gabungan dari bulan Agustus dan Oktober 2018, terdapat produk makanan ringan dengan pembelian sebesar 57\%, sabun mandi dengan merk lifebouy dengan pembelian sebesar $25 \%$, produk pasta gigi dengan merk pepsodent dengan pembelian sebesar $45 \%$ dan produk susu dengan merk frisian flag sebesar $47 \%$, susu dengan merk indomilk sebesar $43 \%$ [2]. Hal tersebut dibuktikan dengan persentase akurasi gabungan Agustus dan Oktober pada gambar di bawah ini :

Gabungan Agustus Dan Oktober 2018

- \% Pembelian

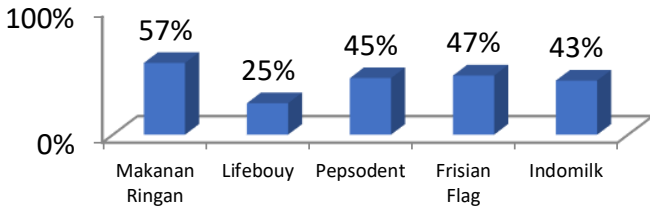

Gambar 1. Hasil Akurasi Pembelian Dari Gabungan Bulan Agustus-Oktober 2018 
Selain itu, produk seperti pembelian beras untuk perbulan hanya didapat sebesar $16 \%$, dimana untuk produk ini pembeliannya secara berkala atau sistem pembeliannya hanya satu kali dalam sebulan (packing karung). Sedangkan item produk pada AB Mart ini ada 50 item, berarti ada sebanyak 44 item produk yang datanya tidak terungkap. Permasalahan ini akan dipecahkan menggunakan analisis data mining[3].

Data Mining adalah proses mengekstrasi informasi atau sesuatu yang yang menarik dari data yang ada didalam database sehingga menghasilkan informasi yang berharga dengan menggunakan teknik-teknik seperti clustering, estimasi, deskripsi, dan lain-lain. Market Basket Analysis (MBA) ini memiliki banyak alternatif solusi yang dapat dipilih sesuai dengan kondisi yang dimiliki oleh pemilik bisnis[4]. Apriori adalah salah satu algoritma yang kerap digunakan pada metode market basket analysisuntuk menemukan pola asosiasi dengan tingkat kepercayaan tertentu melalui minimum support dan minimum confidence [5] . Sehingga output yang dihasilkan dapat membantu pihak minimarket dalam penempatan barang. Algoritma Apriori tetap menjadi algoritma yang paling banyak diterapkan untuk data mining karena mudah dipahami dan diterapkan bila dibandingkan dengan algoritma yang lainnya yang memang diterapkan untuk proses association rule[6].

Hasil yang didapatkan dari proses data mining ini nantinya dijadikan suatu pengetahuan baru yang digunakan pihak minimarket untuk mengetahui barang apa yang biasa dibeli bersamaan, maka dapat menata rakrak barangnya sesuai informasi dan pengetahuan yang telah didapatkannya dalam sebuah area yang saling berdekatan[7].

\section{METODOLOGI PENELITIAN}

\subsection{Kerangka Kerja Penelitian}

Untuk membantu dalam penyusunan penelitian ini, maka perlu adanya susunan kerangka kerja (frame work) yang jelas tahapan - tahapannya. Kerangka kerja ini merupakan langkah-langkah yang akan dilakukan dalam penyelesaian masalah yang akan dibahas. Adapun kerangka kerja penelitian yang digunakan dapat dilihat pada gambar 1[8] :

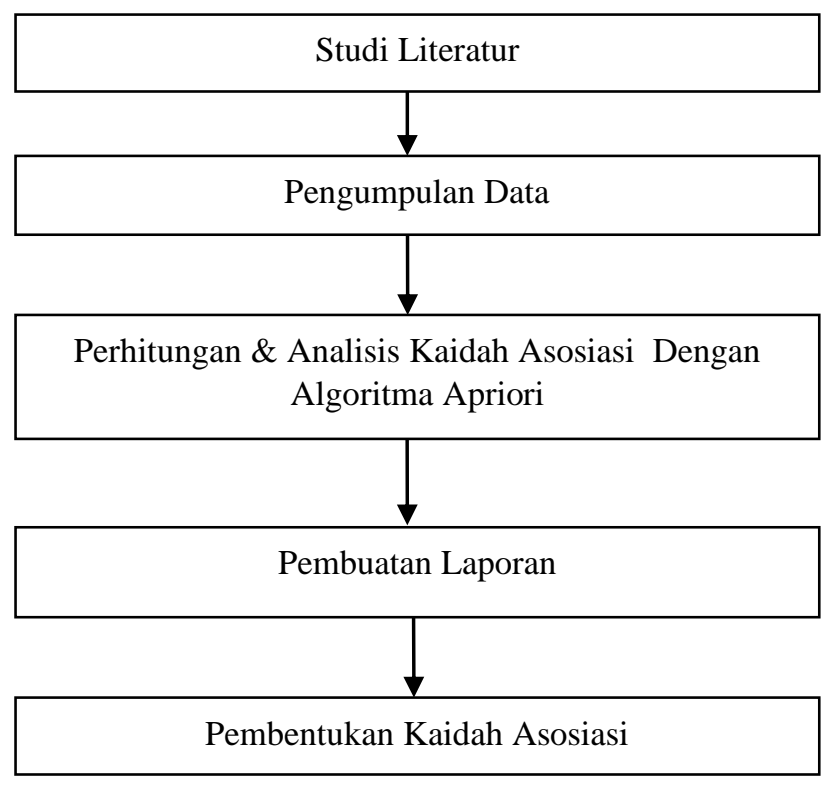

Gambar 2. Kerangka Kerja Penelitian

Berdasarkan kerangka kerja penelitian yang telah digambarkan diatas, maka dapat diuraikan pembahasan masing-masing tahapan dalam penelitian adalah sebagai berikut[9] :

1. Identifikasi Masalah

Tahap pertama dalam penelitian adalah mengidentifikasi masalah yang terdapat pada minimarket AB Mart adalah pola penataan barang yang belum berorientasi pada kecenderungan pola pembelian konsumen. Masalah - masalah yang ada akan dipecahkan mengunakan data mining dengan algoritma Apriori metode market basket analysis.

2. Studi Literatur

Tahap kedua dalam penulisan penelitian ini adalah studi literatur yang digunakan untuk mengumpulkan bahan referensi mengenai Data Mining terutama bagaimana sebuah Algoritma Apriori bisa digunakan dalam mempelajariMarket Basket Analysis dari berbagai buku, e-book, jurnal, paper, artikel dan beberapa referensi lainnya yang ada diperpustakaan STIKOM DB JAMBI.

3. Pengumpulan Data 
Pada pengumpulan data, penulis melakukan pengamatan langsung ke lapangan dan melakukan wawancara pada pemilik AB Mart :

a. Pengamatan Langsung (Observation)

Penelitian dengan metode observation ini dilakukan dengan melakukan pengamatan langsung terhadap objek yang akan diteliti yang bertujuan untuk memperkuat data, mengetahui serta mendapatkan informasi secara langsung bagaimana penataan barang AB Mart. Data transaksi diperoleh dari AB Mart digunakan dalam penelitian berupa data transaksi penjualan yang terjadi dalam kurun waktu 2 bulan operasional $A B$ Mart Agustus dan Oktober 2018.

b. Wawancara (Interview)

Penulis melakukan tanya jawab secara langsung kepada pemilik AB Mart.

4. Perhitungan \& Analisis Kaidah Asosiasi Dengan Algoritma Apriori

Pada Tahap keempat penulis melakukan perhitungan dengan algoritma Apriori. Tahapan dalam algoritma Apriori adalah menentukan minimum support dan minimum confidence untuk menentukan seberapa kuat kaidah asosiasi yang akan dicari, mencari frequent itemset yang memenuhi minimum support yang telah ditetapkan, dan menghitung confidence dari masing-masing frequent itemset, lalu mencari frequent itemset yang memenuhi minimum confidence yang telah ditetapkan[10].

5. Pembentukan Kaidah Asosiasi

Tahap kelima dalam penelitian adalah membentuk kaidah asosiasi dari hasil perhitungan yang telah dilakukan. Setelah semua frequent itemsets ditemukan, dapat langsung dibentuk kaidah asosiasi dari frequent itemsets yang ada. Kaidah asosiasi yang dicari adalah kaidah asosiasi yang memiliki asosiasi kuat, yaitu kaidah-kaidah asosiasi yang memenuhi nilai minimum support dan minimum confidence. Kaidah asosiasi yang telah didapatkan dapat digunakan sebagai acuan untuk melakukan pola perbaikan dalam penataan dan untuk meningkatkan penjualan barang di minimarket AB Mart dengan berorientasi pada item-item yang sering dibeli secara bersamaan[11].

6. Pembuatan Laporan

Pada tahapan terakhir dari proses penelitian ini adalah penyusunan laporan penelitian dengan menggunakan teknik pengumpulan data primer dan data sekunder, sehingga menjadi laporan penelitian yang sesuai dengan analisis yang sedang diteliti.

7. Rumus dan langkah menghitung support dan confidence

$$
\begin{aligned}
& \text { SUPPORT }=\frac{\sum \text { transaksi mengandung A dan B }}{\sum \text { jumlah seluruh transaksi }} \times 100 \% \\
& \text { CONFIDENCE }=\frac{\sum \text { transaksi mengandung A dan B }}{\sum \text { transaksi mengandung A }} \times 100 \%
\end{aligned}
$$

Disini dapat dilihat untuk mendapatkan nilai support yaitu jumlah transaksi yang mengandung A dan B dibagi jumlah seluruh transaksi kemudian dikali 100\%. Begitu juga dengan cara mendapatkan nilai confidence yaitu jumlah transaksi yang mengandung A dan B dibagi Jumlah transaksi yang mengandung A dikali $100 \%[12]$

\section{HASIL DAN PEMBAHASAN}

Setelah dilakukannya analisis asosiasi dengan menggunakan tools WEKA, maka didapatlah hasil yang berbedabeda tiap periode. Perbandingan hasil analisis dapat dilihat pada tabel di bawah ini :

Tabel 1. Perbandingan Data Penjualan

\begin{tabular}{llll}
\hline Parameter & $\begin{array}{l}\text { Gabungan Agustus dan } \\
\text { Oktober }\end{array}$ & Agustus & Oktober \\
\hline \multirow{2}{*}{ Rule } & $\begin{array}{l}\text { Pepsodent, Frisian Flag, } \\
\text { Indomilk }\end{array}$ & $\begin{array}{l}\text { Pepsodent, Frisian Flag, Gula } \\
\text { Pasirkg, Indomilk, beras Jempol }\end{array}$ & $\begin{array}{l}\text { Pepsodent, Frisian Flag, } \\
\text { Indomilk, Chil }\end{array}$ \\
Support & 800 & 397 & 403 \\
Confidence & 0,1 & 0,1 & 0,1 \\
& 0,9 & 0,9 & 0,9 \\
Jumlah Item & Pepsodent $=102$ & Pepsodent $=53$ & Prisian Flag $=44$ \\
& Frisian Flag $=90$ & Gula Pasirkg $=44$ & Flag $=46$ \\
& Indomilk $=88$ & Indomilk $=43$ & Frisian \\
& & beras Jempol=42 & Chdomilk $=45$ \\
\end{tabular}

Tabel di atas merupakan perbandingan data penjualan perperiode. Periode Gabungan Agustus dan Agustus terdapat 3 rule, yaitu Pepsodent dengan jumlah 102, Frisian Flag dengan jumlah 90, dan Indomilk dengan julah 88 dari instances 800 item. Periode ini memiliki support 0,1 dan confidence 0,9. Periode Agustus 
terdapat 5 rule, yaitu Pepsodent dengan jumlah 53, Frisian Flag dengan jumlah 44, Gula Pasirkg dengan jumlah 44, Indomilk dengan jumlah 43, dan Beras Jempol dengan jumlah 42 dari instances 397 item. Periode ini memiliki support 0,1 dan confidence 0,9. Periode Oktober terdapat 4 rule, yaitu Pepsodent dengan jumlah 49, Frisian Flag dengan jumlah 45, Indomilk dengan jumlah 45, dan Chil dengan jumlah 45 dari instances 403 item. Periode ini memiliki support 0,1 dan confidence $0,9[13]$.

Tabel 2. Persentasi Akurasi Gabungan Agustus dan Oktober

\begin{tabular}{llll}
\hline \multicolumn{2}{l}{ Gabungan Agustus dan Oktober } & & \\
& Pepsodent & Frisian Flag & Indomilk \\
\hline Jumlah Item Di beli & 102 & 90 & 88 \\
Jumlah Total Item & 46 & 46 & 46 \\
$\%$ Pembelian & $221,74 \%$ & $195,65 \%$ & $191,30 \%$ \\
\hline
\end{tabular}

Dari tabel di atas dapat dijelaskan bahwa transaksi penjualan AB Mart pada bulan Agustus dan Oktober menghasilkan atau men-generate hubungan antar item produk belanja. Dengan perhitungan Algoritma Asosiasi Apriori ditemukan hubungan Market Basket Analysis antara produk Pepsodent, Frisian Flag dan Indomilk. Dengan Rule[14] :

1. IF Buy Pepsodent AND Frisian Flag, THEN Buy Indomilk

2. IF Buy Pepsodent AND Indomilk, THEN Buy Frisian Flag

3. IF Buy Frisian Flag AND Indomilk, THEN Buy Pepsodent

Rule tersebut dihasilkan dari nilai support dan confidence tertinggi dari keseluruhan nilai support dan confidence item lainnya. Nilai support tertinggi adalah sebesar 0.1 dan nilai confidence tertinggi adalah 0.9. Hasil Akurasi Analisis Asosiasi Apriori Gabungan Austus dan Oktober :

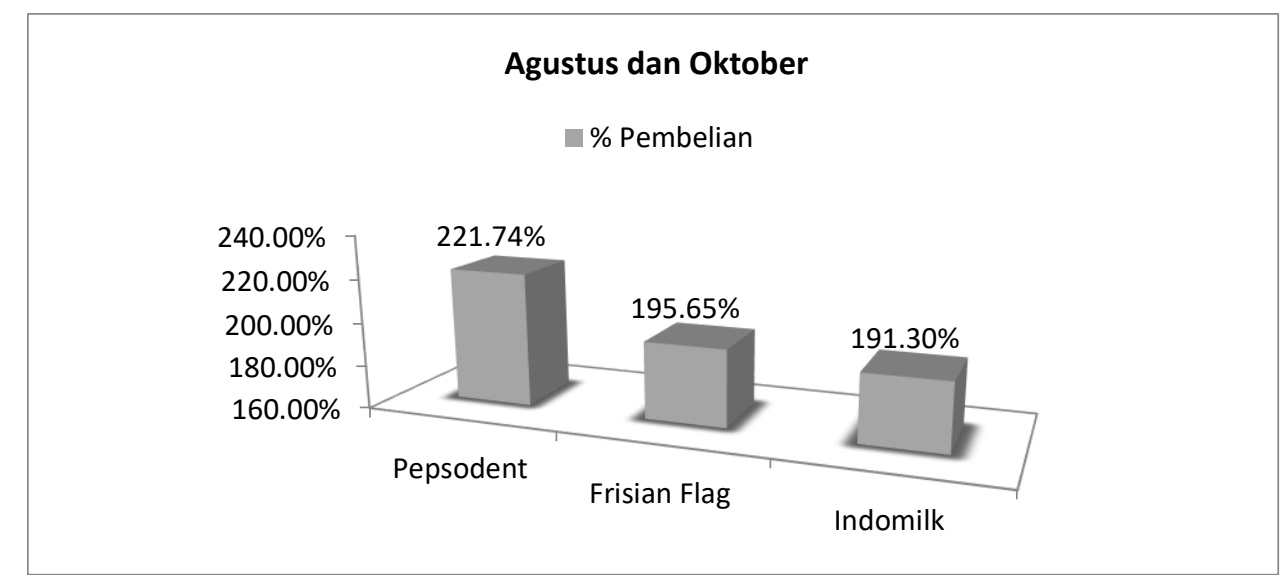

Gambar 3. Hasil Akurasi Analisis Asosiasi Apriori Gabungan Agustus-Oktober

Gambar 5 merupakan grafik persentasi hasil analisis apriori gabungan Agustus-Oktober dengan nilai persentasi tertinggi yaitu Pepsodent sebesar 2231,74\%, Frisian Flag sebesar 195,65\% dan Indomilk sebesar $191,30 \%[15]$.

\subsection{Hasil Analisis Asosiasi Bulan Agustus}

Berikut merupakan hasil analisis Asosiasi Bulan Agustus :

Tabel 3. Persentasi Akurasi Bulan Agustus

\begin{tabular}{llllll}
\hline Agustus & Fepsodent & Frisian Flag & $\begin{array}{l}\text { Gula } \\
\text { Pasirkg }\end{array}$ & Indomilk & $\begin{array}{l}\text { Beras } \\
\text { Jempol }\end{array}$ \\
\hline Jumlah Item Di beli & 53 & 44 & 44 & 43 & 42 \\
Jumlah Total Item & 46 & 46 & 46 & 46 & 46 \\
$\%$ Pembelian & $115 \%$ & $96 \%$ & $96 \%$ & $93 \%$ & $91 \%$ \\
\hline
\end{tabular}

Dari tabel di atas dapat dijelaskan bahwa transaksi penjualan AB Mart pada bulan Agustus menghasilkan atau men-generate hubungan antar item produk belanja. Dengan perhitungan Algoritma Asosiasi Apriori ditemukan hubungan Market Basket Analysis antara produk Pepsodent, Frisian Flag, Gula Pasirkg, Indomilk dan Beras Jempol. Dengan Rule[16] :

1. IF Buy Pepsodent, Buy Frisian Flag, Buy Gula Pasirkg AND Buy Indomilk, THEN Buy Beras Jempol.

2. IF Buy Pepsodent, Buy Frisian Flag, Buy Gula Pasirkg AND Buy Beras Jempol, THEN Buy Indomilk.

3. IF Buy Pepsodent, Buy Frisian Flag, Buy Indomilk AND Buy Beras Jempol, THEN Buy Gula Pasirkg. 


\section{JURNAL MEDIA INFORMATIKA BUDIDARMA}

Volume 5, Nomor 2, April 2021, Page 676-681

ISSN 2614-5278 (media cetak), ISSN 2548-8368 (media online)

Available Online at https://ejurnal.stmik-budidarma.ac.id/index.php/mib DOI 10.30865/mib.v5i2.2934

4. IF Buy Pepsodent, Buy Indomilk, Buy Beras Jempol AND Buy Gula Pasirkg, THEN Buy Frisian Flag.

5. IF Buy Frisian Flag, Buy Gula Pasirkg, Buy Indomilk AND Buy Beras Jempol, THEN Buy Pepsodent.

Rule tersebut dihasilkan dari nilai support dan confidence tertinggi dari keseluruhan nilai support dan confidence item lainnya. Nilai support tertinggi adalah sebesar 0.1 dan nilai confidence tertinggi adalah 0.9. Hasil Akurasi Analisis Asosiasi Apriori Bulan Agustus:

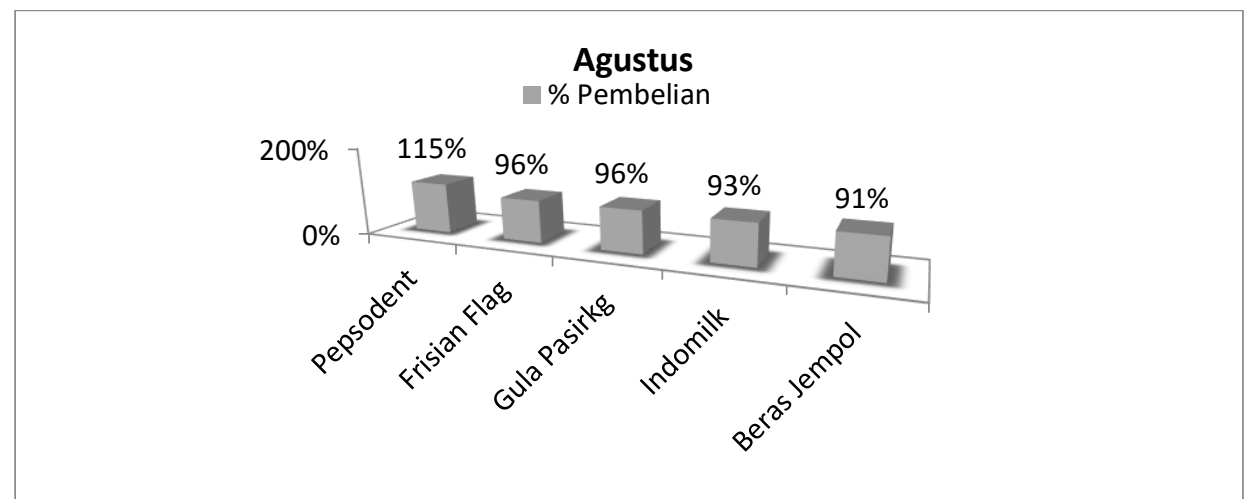

Gambar 4. Hasil Akurasi Analisis Asosiasi Apriori Bulan Agustus

Gambar 4 merupakan grafik persentasi hasil analisis apriori bulan Agustus dengan nilai persentasi tertinggi yaitu Pepsodent sebesar 115\%, Frisian Flag sebesar 96\%, Gula Pasirkg sebesar 96\%, Indomilk sebesar 93\% dan Beras Jempol 91\%.

\subsection{Hasil Analisis Asosiasi Bulan Oktober}

Berikut merupakan hasil analisis Asosiasi Bulan Oktober :

Tabel 4. Persentasi Akurasi Bulan Oktober

\begin{tabular}{lllll}
\hline Oktober & & Frisian & & \\
& Pepsodent & Flag & Indomilk & Chil \\
\hline Jumlah Item Di beli & 49 & 46 & 45 & 45 \\
Jumlah Total Item & 46 & 46 & 46 & 46 \\
$\%$ Pembelian & $107 \%$ & $100 \%$ & $98 \%$ & $98 \%$ \\
\hline
\end{tabular}

Dari tabel di atas dapat dijelaskan bahwa transaksi penjualan AB Mart pada bulan Oktober menghasilkan atau men-generate hubungan antar item produk belanja. Dengan perhitungan Algoritma Asosiasi Apriori ditemukan hubungan Market Basket Analysis antara produk Pepsodent, Frisian Flag, Indomilk, Chil. Dengan Rule[17] :

1. IF Buy Pepsodent, Buy Frisian Flag AND Buy Indomilk, THEN Buy Chil.

2. IF Buy Pepsodent, Buy Frisian Flag AND Buy Chil, THEN Buy Indomilk.

3. IF Buy Pepsodent, Buy Indomilk AND Buy Chil, THEN Buy Frisian Flag.

4. IF Buy Frisian Flag, Buy Indomilk AND buy Chil, THEN Buy Pepsodent.

Rule tersebut dihasilkan dari nilai support dan confidence tertinggi dari keseluruhan nilai support dan confidence item lainnya. Nilai support tertinggi adalah sebesar 0.1 dan nilai confidencetertinggi adalah 0.9. Hasil Akurasi Analisis Asosiasi Apriori Bulan Oktober:

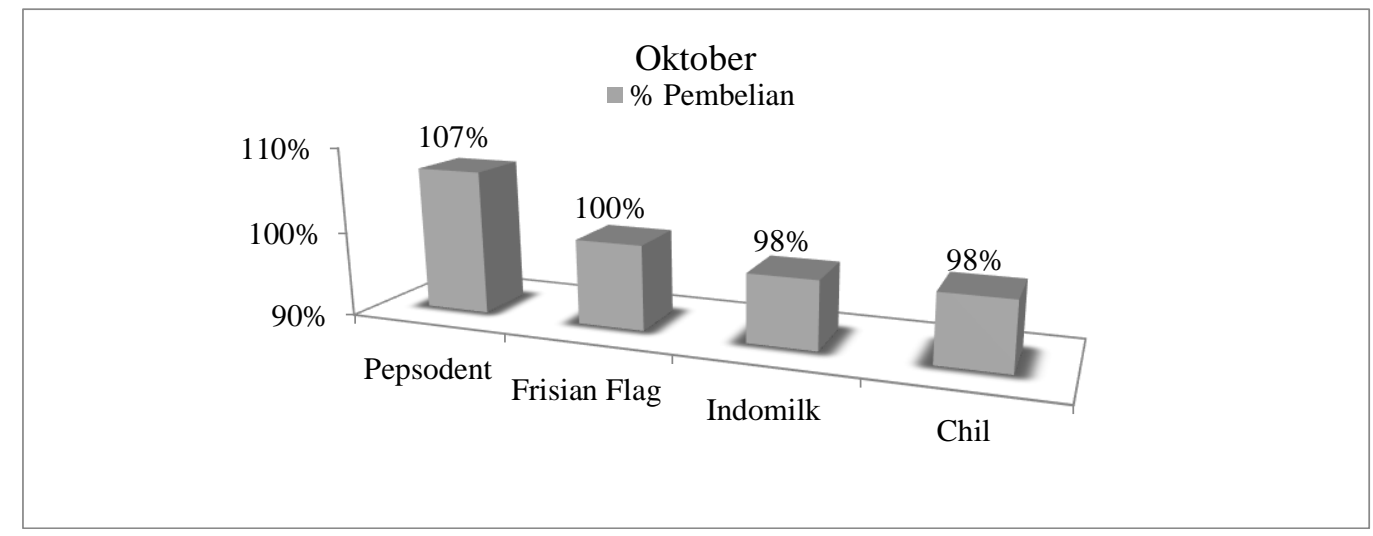

Gambar 5. Hasil Akurasi Analisis Asosiasi Apriori Bulan Oktober 
Gambar 5 merupakan grafik persentasi hasil analisis apriori bulan Oktober dengan nilai persentasi tertinggi yaitu Pepsodent sebesar 107\%, Frisian Flag 100\%, Indomilk 98\%, dan Chil 98\%.

\section{KESIMPULAN}

Penelitian ini menerapkan metode Market Basket Analysis (MBA) dengan algoritma apriori. Data yang digunakan adalah bulan Agustus dan Oktober 2018. Hasil pengujian menggunakan software Weka dengan algoritma apriori menghasilkan hubungan asosiasi antara barang pepsodent dengan jumlah transaksi yang dibeli sebesar 102, frisian flag dengan jumlah transaksi yang dibeli sebesar 90, dan indomilk dengan jumlah transaksi yang dibeli sebesar 88. Sehingga akan menghasilkan asosiasi sebanyak 3 rule, yaitu :IF Buy Pepsodent AND Frisian Flag, THEN Buy Indomilk, IF Buy Pepsodent AND Indomilk, THEN Buy Frisian Flag dan, IF Buy Frisian Flag AND Indomilk, THEN Buy Pepsodent .Hasil hubungan asosiasi di atas didapat dari nilai support sebesar 0.1 dan nilai confidence sebesar 0.9 secara keseluruhan. Rule tertinggi yang dihasilkan pada pepsodent, frisian flag dan indomilk akan digunakan untuk rekomendasi perbaikan tata letak produk AB Mart.

\section{UCAPAN TERIMAKASIH}

Terimakasih disampaikan kepada pihak-pihak yang telah mendukung terlaksananya penelitian ini.

\section{REFERENCES}

[1] Aditya, F. Marisa, and Purnomo, "Penerapan Algoritma Apriori Terhadap Data Penjualan di Toko Gudang BM,” 2016.

[2] Alfiqra and A. Faiza Yogi, "Penerapan Market Basket Analysis Menggunakan Proses Kdd (Knowledge Discovery In Database) Sebagai Strategi Penjualan Produk Swalayan (Studi Kasus : Swalayan X) Alfiqra,” 2018.

[3] R. Halim and Alam Jusia, "Perancangan Market Basket Analysis Menggunakan Association Rule untuk Pendukung Keputusan Promosi pada Sistem Penjualan Sun Young Cel," pp. 964-973, 2017.

[4] N. . Hasibuan, "Implementasi Data Mining Untuk Pengaturan Layout," pp. 6-11, 2017.

[5] F. . Hermawati, Data Mining. CV.ANDI OFFEST, 2013.

[6] Hemawati, “Analisis Market Basket Dengan Algoritma Apriori (Study Kasus Toko Alief)," pp. 13-17, 2018.

[7] S. Kalmegh, "Analysis of WEKA Data Mining Algorithm REPTree, Simple Cart and RandomTree for Classification of Indian News," pp. 438-446, 2015.

[8] S. Kuswayati and D. Tjahyadi, "Market Basket Analysis Menggunakan Algoritma Apriori Untuk Penetapan Strategi Bundling Penjualan Barang," pp. 1-18, 2015.

[9] A. K. Prasidya and Fibriani, "Pembelian Menggunakan Data Mining Dengan Algoritma Apriori ( Studi Kasus : Minimarket Gun Bandungan , Jawa Tengah ),” vol. 15, pp. 173-184, 2017.

[10] D. Nofriansyah, Konsep Data Mining VS Sistem Pendukung Keputusan. Yogyakarta: DEEPUBLISH, 2014.

[11] Nurdin and D. Astika, "Penerapan Data Mining Untuk Menganalisis Penjualan Barang Dengan Pada Supermarket Sejahtera Lhokseumawe," pp. 134-155, 2015.

[12] L. . Prahartiwi, "Pencarian Frequent Itemset pada Analisis Keranjang Belanja Menggunakan Algoritma FP-Growth," pp. 1-10, 2017.

[13] H. Santoso, I. . Hariyadi, and Prayitno, "Data Mining Analisa Pola Pembelian Produk', Teknik Informatika," pp. 1924, 2016.

[14] S. . Shona Chay Bilqisth, "Analisis pola pembelian konsumen dengan algoritma apriori pada indomaret indraprasta semarang," p. 207, 2015.

[15] A. Thoriq Muhammad and B. Nurhadiyono, "Penerapan Data Mining Pada Data Transaksi Penjualan Untuk Mengatur Penempatan Barang," 2014.

[16] M. . Tana, "Penerapan Metode Data Mining Market Basket Analysis Terhadap Data Penjualan Produk Pada Toko Oase Menggunakan Algoritma Apriori," pp. 17-22, 2018.

[17] N. Silalahi, "Penerapan Association Rule Dengan Algoritma Apriori Untuk," pp. 114-123, 2016. 